\title{
DEPÓSITO DE GRAFITA DA FAZENDA TRAÍRAS (BA): UM EXEMPLO DE ROMBOCASMO DESENVOLVIDO EM UMA ZONA DE CISALHAMENTO
}

\author{
Ronald Fleischer (*) \& Saulo Augusto de Oliveira (*)
}

\begin{abstract}
A flaky graphite deposit is described with emphasis on the chemical-mineralogical characterization of its main graphite bearing lithologies, namely graphite "gneisses" and graphitic breccias.

The proposed geological model for the deposit is based on the development of a shear zone affecting archean metamorphic rocks in a deep crustal environment which was the channelway for an ultrabasic intrusion.

Graphite concentrations are restricted to milonitic belts which cut the ultrabasic intrusive.

An attempt is made to compare the geological characteristics of this deposit with other graphite deposits in Brazil and elsewhere.
\end{abstract}

Palavras-chave: Grafita, Rombocasmo, Zona de Cisalhamento, Intrusões Ultrabásicas.

\section{INTRODUÇÃOO}

A ocorrência de grafita da Fazenda Traíras, município de Itatim (ex-Santa Terezinha) a cerca de $120 \mathrm{Km}$ ao sul de Feira de Santana (fig.1) já encontra referências na literatura especializada (Mascarenhas $e t$ al. 1979), sem que existam entretanto maiores informações a respeito do tipo de depósito, seja com relação às características da grafita propriamente dita, seja com respeito ao cenário geológico, na qual a mesma se desenvolveu. O objetivo deste trabalho é o de oferecer uma contribuição ao melhor conhecimento da ocorrência e de suas relações com o quadro geológico regional, sendo resultado de trabalhos de pesquisa mineral.

\section{ESBOÇO DA GEOLOGIA REGIONAL}

A ocorrência da Fazenda Traíras situa-se no contexto do Complexo Jequié ou Complexo Migmatítico - Granulítico da Bahia, de Pedreira et al. (1975), constituído por um conjunto de rochas metamórficas de médio/alto grau de idade arqueana. (Fig. 2)

Litologicamente predominam na área gnaisses, migmatitos e anfibolitos (Sampaio \& Silva Filho 1986). Idades radiométricas de 2,6 a 2,7 Ga. foram obtidas para essas rochas pelo método $\mathrm{Rb}-\mathrm{Sr}$, indicando deformação de rochas pré-existentes durante o importante ciclo tectono termal denominado Jequié, segundo Cordani (in Mascarenhas et al. 1979). Ainda segundo este autor o conjunto foi retrabalhado no ciclo Transamazônico (2,0 Ga.) ocorrendo então recristalizações, (adição de material do manto de natureza granodiorítica) e definição das feições estruturais maiores de orientação NW/SE.

Pequenas porções do Complexo Jequié são cobertas por sedimentos inconsolidados da Formação Capim Grosso, de Brito Neves \& Feitosa, (in Mascarenhas et al. 1979), supostamente de idade terciária, representados por conglomerados monomíticos em matriz arenosa e arenitos argilosos fracamente selecionados, que não ocorrem na área em apreço.

\section{GEOLOGIA DO DEPÓSITO}

\section{Estruturas}

O depósito estudado está situado na ramificação de uma zona de cisalhamento de direção N50W cortando gnaisses e diatexitos do Complexo Jequié, com extensão aproximada de $20 \mathrm{~km}$, e com uma importante componente de movimentação horizontal identificável por uma forte lineação sub-horizontal, com plunge de $10^{\circ} \mathrm{NW}$.

Na região dos Morros do Bernardino, João Congo e Gameleira, essa "dicotomização" delineou um ROMBOCASMO (do inglês_Rhombochasm: a parallel - sided gap in the sialic crust occupied by simatic crust" - Bates \& Jackson 1980), isto é, uma estrutura grosseiramente losangular contendo no seu interior rochas ultrabásicas, transformadas ou não, e estruturadas de maneira diferente daquelas do substrato encaixante. Essa estrutura encontra ótima representação no modelo de Quennel ( in Seyfert 1987).

O rombocasmo em questão, tem uma extensão NWSE de $14 \mathrm{~km}$ e uma largura média de $1 \mathrm{~km}$, sendo balizado em todos os lados por milonitos quartzosos de direção marcadamente NW-SE e mergulhos fortes para NE $\left(60^{\circ}\right.$ até $\left.90^{\circ}\right)$, contrastando com a atitude dos 


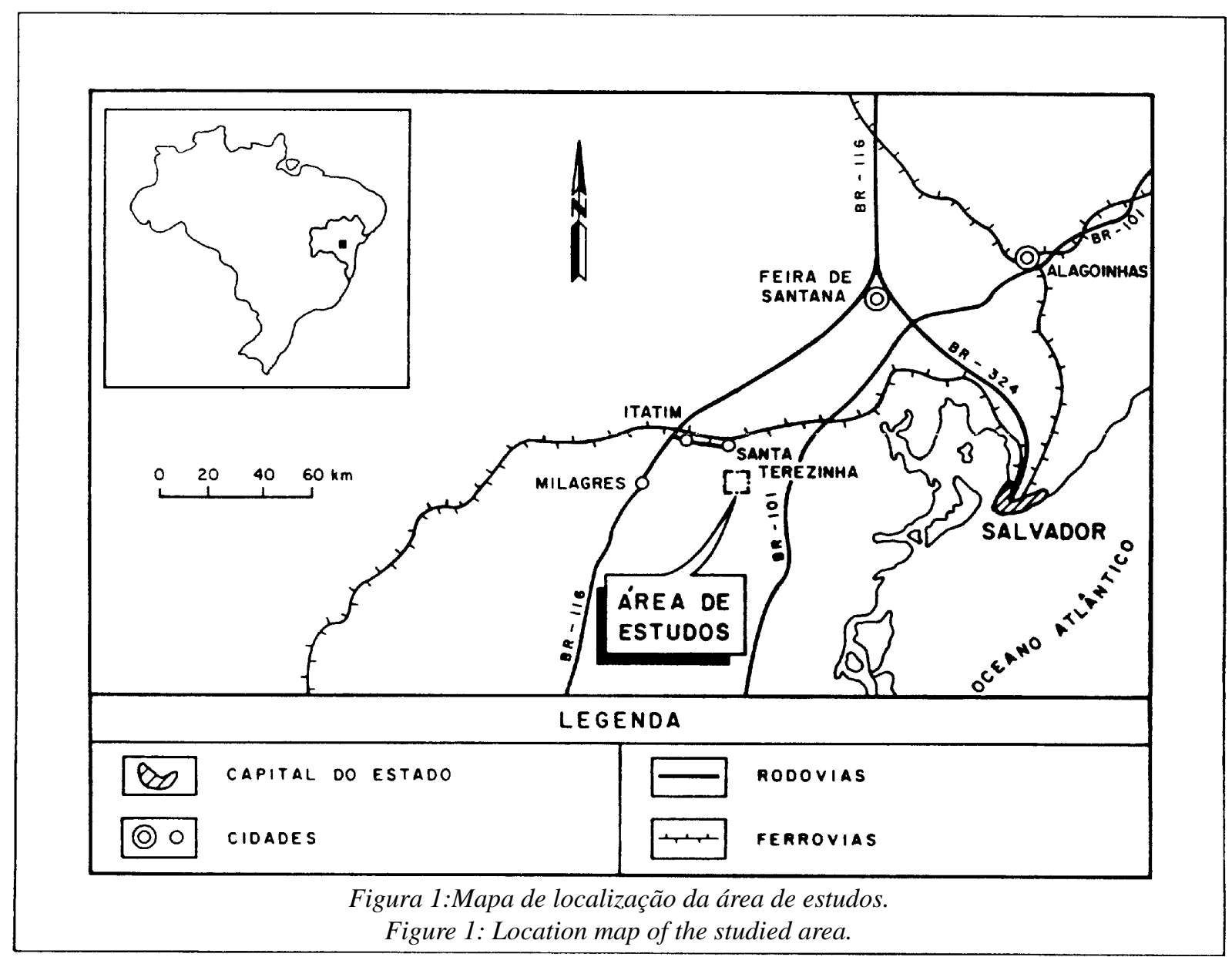

gnaisses encaixantes que mostram uma foliação ondulada de orientação geral NW-SE e mergulhos suaves para NE $\left(20^{\circ}\right.$ a $\left.30^{\circ}\right)$.

No interior do rombocasmo ocorrem várias zonas de cisalhamento, também de direção NW-SE e mergulhos fortes para NE, que são bem marcadas por anomalias geofísicas de eletrorresistividade.

Com base: a) na morfologia tabular e com forte mergulho para NE dos tipos litológicos no interior do rombocasmo (principalmente dos corpos tabulares grafitosos); b) em uma foliação gnaissica no interior destes corpos; c) e em uma forte lineação conferida por orientação de prismas milimétricos de quartzo na borda de veios de quartzo bandados e d) no fato de estar-se num ambiente tectônico de deformação intensa e penetrativa onde o plano de foliação contém os eixos XY definiu-se a orientação dos três eixos do elipsóide de deformação finita para a estrutura em questão, importante para a avaliação das reservas existentes. A lineação citada, de atitude N 10-20 W / 10-SE, coincide com a orientação de agregados quartzo-feldspáticos entre escamas de grafita, onde este mineral é abundante. Ela corresponde a uma lineação de estiramento, definindo o eixo X (maior) do elipsóide, que pela sua atitude sub-horizontal mostra também de maneira aproximada a extensão longitudinal dos corpos grafíticos. $\mathrm{O}$ eixo $\mathrm{Y}$ (intermediário) é perpendicular à lineação de estiramento no plano de sondagem e apresenta forte mergulho $\left(65^{\circ}\right.$ a $80^{\circ}$ para NE), muito próximo ao mergulho geral das rochas no interior do rombocasmo; é de se esperar que confira aos corpos grafíticos uma dimensão da mesma ordem de grandeza àquela do eixo $X$, ou seja, de algumas centenas de metros. Ao eixo $\mathrm{Z}$ (menor) corresponderia a menor dimensão dos corpos grafitosos, isto é, a sua espessura.

O modelo de geração do rombocasmo e, conseqüentemente, do depósito estudado, segundo o elipsóide de deformação finita estabelecido, mostra um regime transcorrente. Ele é dextral o que numa inflexão para a direita, como ocorre localmente na Faz. Trairas, cria um regime transtrativo.

A Figura 2 representa esquematicamente em planta a estrutura que caracteriza o depósito.

\section{Litologias}

$\mathrm{Na}$ zona externa ao rombocasmo ocorrem gnaisses dominantemente a quartzo, plagioclásio, anfibólios e biotita. Apresentam-se bandados e de granulação fina a média. Localmente observam-se evidências de fusão parcial, pelo aparecimento de diatexitos e migmatitos.

A grande estrutura cisalhante é marcada ora por filonitização dos gnaisses, acompanhada por stringers de quartzo de veio, ora por quartzomilonitos verdadeiros filões de quartzo estirado - com espessura de decímetros até alguns metros.

No interior do rombocasmo o litótipo principal é uma rocha meta ultrabásica que conforme seu grau de deformação se apresenta sob a forma maciça, verde 


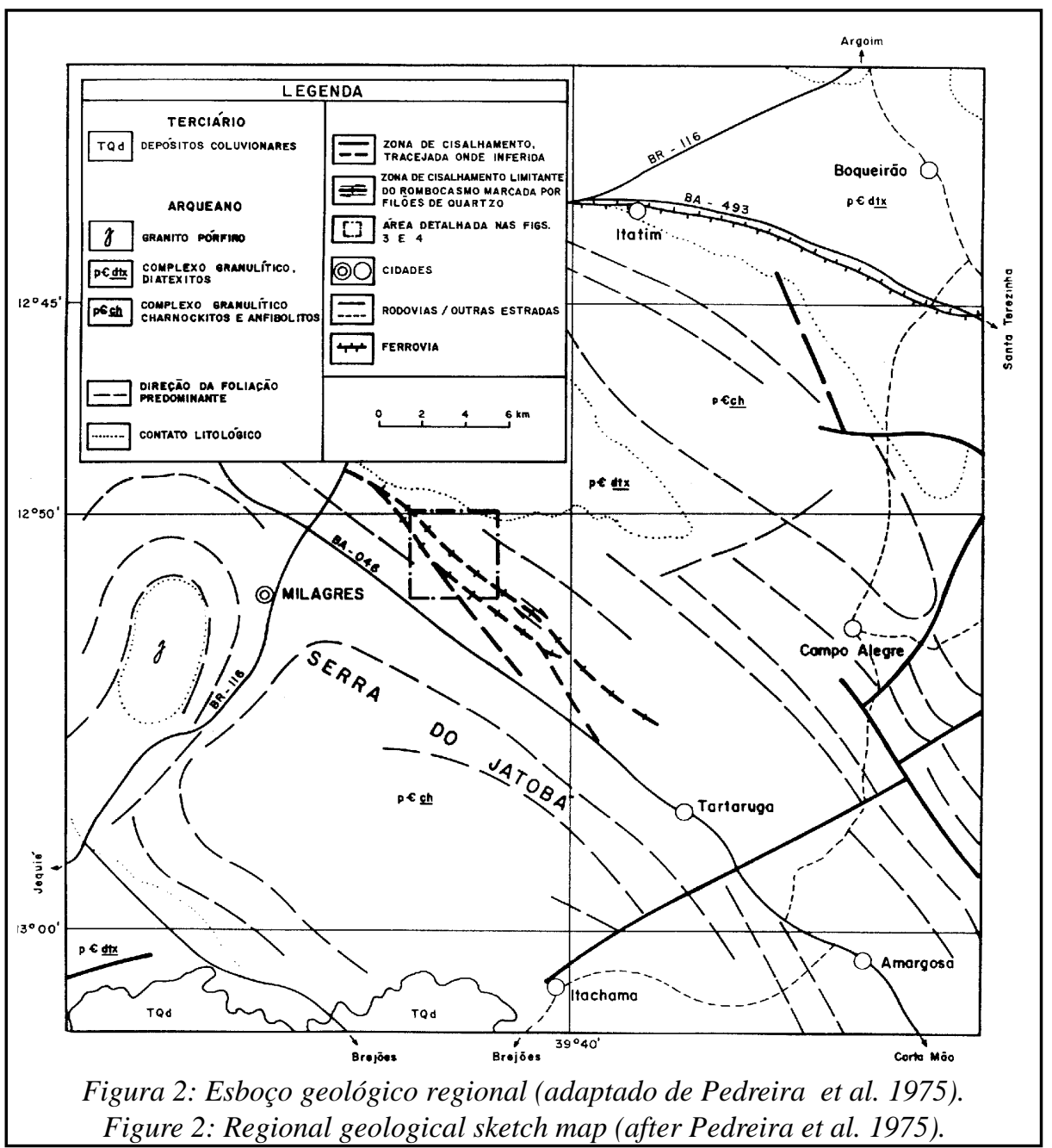

escura, com grã média/grosseira só levemente orientada, até um quartzo-anfibólio-epidoto xisto completamente orientado. Nos núcleos pouco deformados a rocha é petrograficamente caracterizada como um meta augita-hornblendito, praticamente biminerálica, composta por $60 \%$ de anfibólio (hornblenda) e $40 \%$ de piroxênio (augita), em grãos bem preservados e orientados, com textura granonematoblástica. A presença marcante de piroxênio e a boa definição dos contornos dos grãos sugerem tratar-se de um meta-ultrabasito.

Várias zonas de cisalhamento cortam estes ultrabasitos, algumas estendendo-se por mais de 2.000 $\mathrm{m}$, e com uma largura de até $40 \mathrm{~m}$. Tanto no interior destas zonas, como fora delas, observa-se uma zonalidade litológica bastante regular. No exterior das faixas de cisalhamento a zonalidade refere-se ao grau de deformação dos ultrabasitos, maciços e bem preservados longe das zonas de cisalhamento e cada vez mais intensamente foliados quanto mais próximos das mesmas. Nas zonas de cisalhamento, a zonalidade é definida por milonitos quartzosos, nas bordas encaixando uma grande variedade de milonitos na parte central, destacando-se nestes últimos:

a) milonitos quartzo-feldspáticos de grã fina e cor cinza-esbranquiçada contendo epidoto;

b) milonitos quartzo-ferruginosos ocasionalmente ricos em granada grosseira ;ou

c) cataclasitos com textura brechóide com fragmentos angulosos da encaixante meta-ultrabásica ou de quartzo fraturado, imersos numa matriz de quartzo de grã fina.

A rocha mais interessante do ponto de vista econômico e que talvez se constitua numa chave para deslindar a evolução do rombocasmo são os "gnaisses" a quartzo, feldspato e grafita. Trata-se de uma rocha laminada onde a grafita ocorre sob a forma lamelar, com cristais atingindo até $3 \mathrm{~mm}$. Estes grafita-gnaisses ocorrem no interior das zonas de cisalhamento sob a forma de lentes cujas espessuras variam desde 0,5 a 9 m e cujas extensões são da ordem de centenas de metros. No interior de uma só zona de cisalhamento podem ocorrer várias lentes paralelas de "gnaisses" grafíticos.

Um outro litótipo rico em grafita, são as "brechas grafitosas" que embora estejam dispostas segundo planos paralelos à foliação dos milonitos não apresentam nenhuma estruturação interna clara. Contém grafita muito fina e estão freqüentemente acompanhadas por filmes de óxidos ferro-manganesíferos. Em termos de dimensões chegam a ter extensão de centenas de metros e espessuras de até $1,5 \mathrm{~m}$.

No interior do rombocasmo foram reconhecidas quatro zonas de cisalhamento contendo no seu interior lentes de "grafita gnaisses" e "brechas grafitosas". Tais 
zonas de cisalhamento são referidas como CORPOS mineralizados em grafita, e têm características distintas entre si.

O Corpo 1 é o mais importante sob o ponto de vista de expressão em superfície, com extensão superior a 3 km e espessura aparente de até $62 \mathrm{~m}$; contém até 9 lentes do tipo grafita-gnaisse intercaladas com milonitos bandados e "brechas grafitosas". O Corpo 2 é o segundo em expressão, com extensão observada de $2,3 \mathrm{~km}$ e espessura média de $12 \mathrm{~m}$, contendo até 3 lentes de grafitagnaisse formando um conjunto sub-paralelo ao Corpo 1 e distante deste cerca de $80 \mathrm{~m}$ para NE. O Corpo 3 é descontínuo em superfície, consistindo de lentes alinhadas de grafita do tipo brechóide, numa extensão total de 800m, fica para SW do Corpo 1 a uma distância variando de 40 a $120 \mathrm{~m}$. O Corpo 4 constitui-se por até 6 lentes de grafita-gnaisse junto a quartzo-milonitos e "brechas" grafitosas; a extensão verificada para este corpo foi de $800 \mathrm{~m}$ com espessura de até $7 \mathrm{~m}$.

Nos corpos 1, 2 e 4, a continuidade lateral dos corpos grafíticos foi verificada por meio de levantamento geofísico (eletroresistividade) e por trincheiras. A continuidade vertical foi comprovada por poços com até $10 \mathrm{~m}$ de profundidade e por anomalias geofísicas para além de $10 \mathrm{~m}$. No caso do Corpo 3 a grafita parece interromper-se em profundidade antes dos $40 \mathrm{~m}$, o que não exclue a provável continuidade da estrutura milonítica favorável à ocorrência de grafita.

As relações espaciais entre os citados corpos contendo grafita, podem ser observadas no mapa e perfil geológico das figuras 3 e 4 . A Figura 5 é um corte geológico representativo do corpo grafitoso 1 , o mais importante.

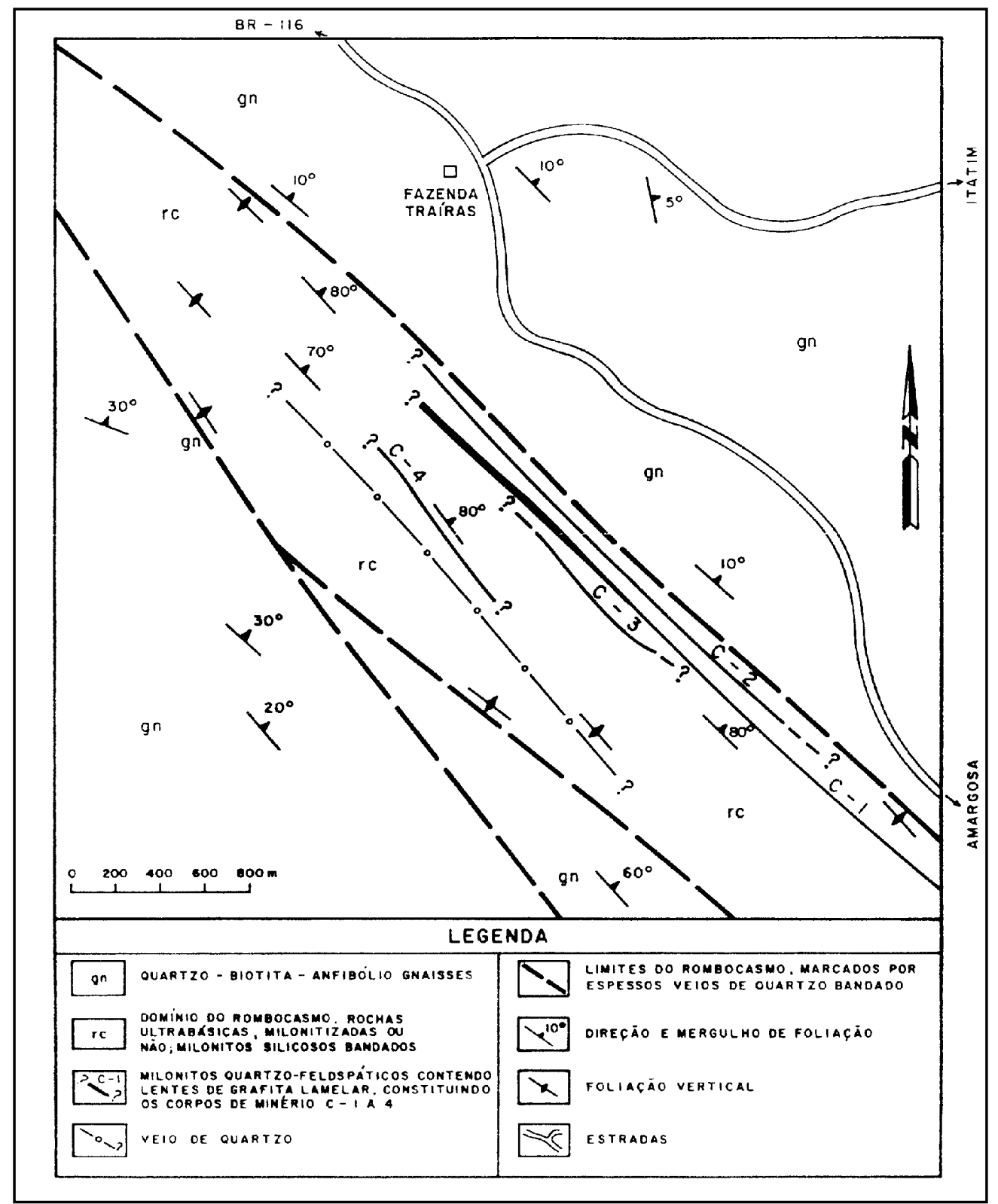

Figura 3:Mapa geológico simplificado da área de estudos.

Figure 3: Geologic sketch map of the studied area. 


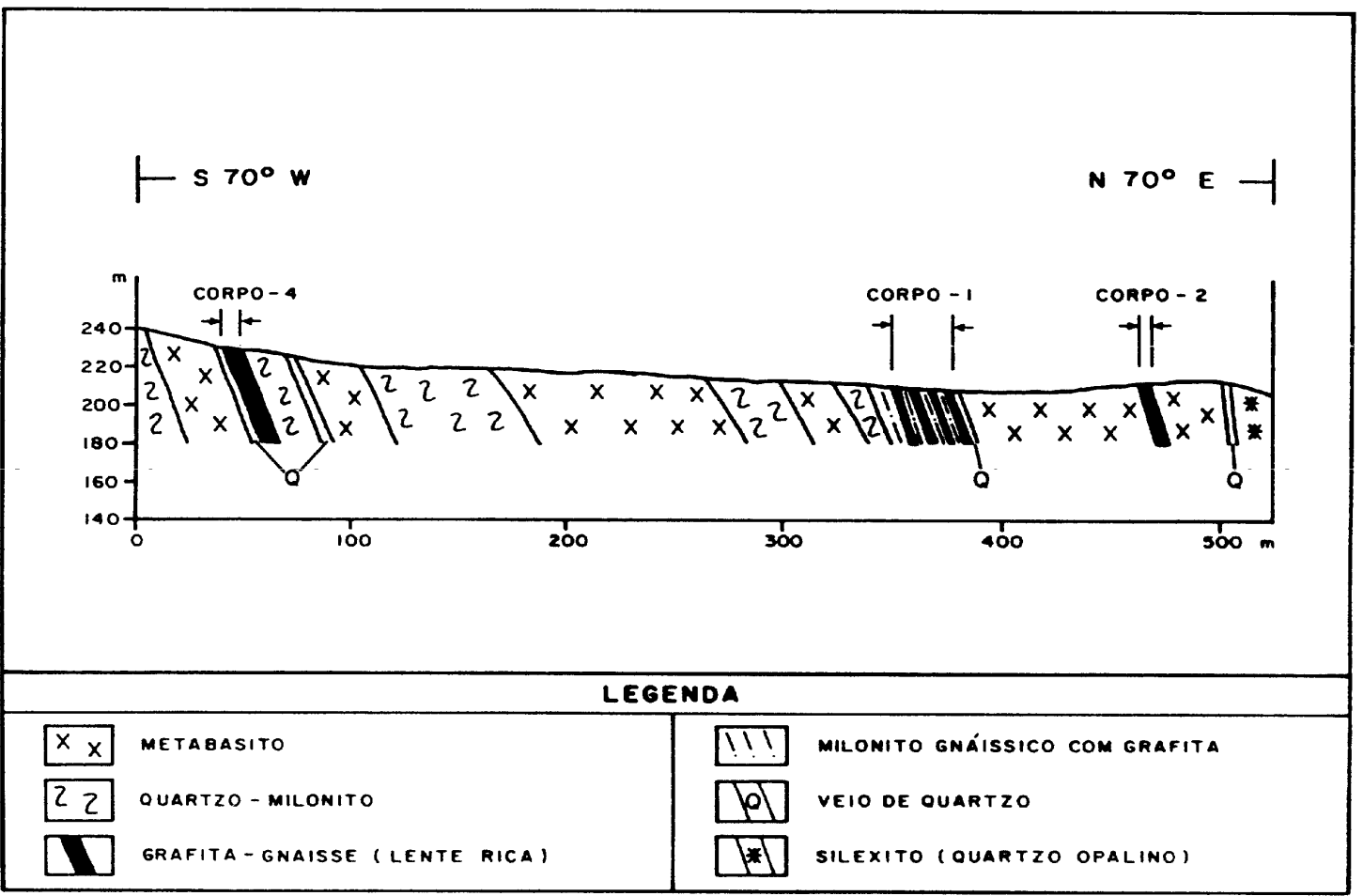

Figura 4: Seção geológica vertical típica do depósito.

Figure 4: Typical geological section of the deposit.

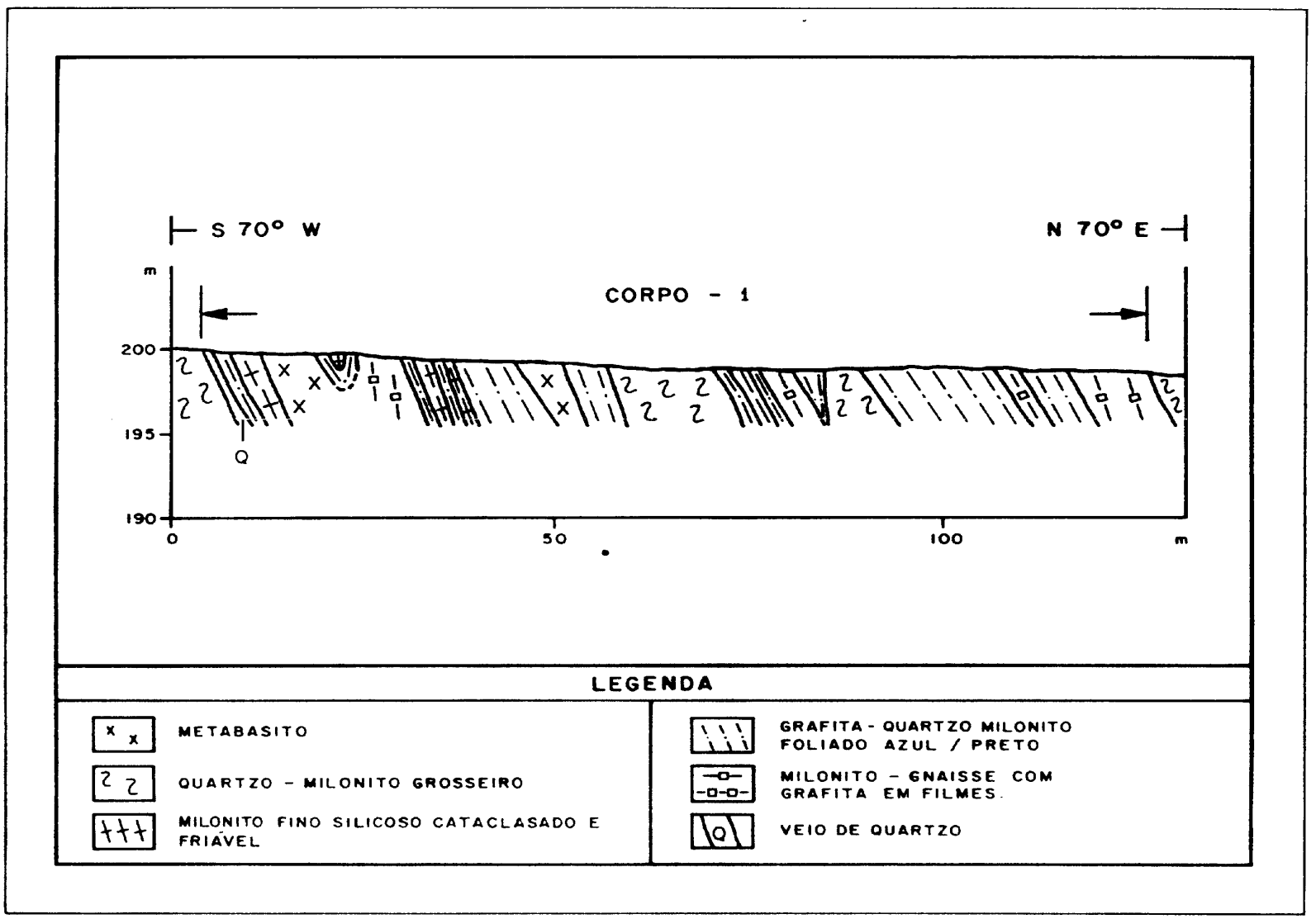

Figura 5:Seção geológica vertical do corpo grafitoso principal.

Figure 5: Geological section of the principal graphite bearing ore body. 


\section{ASPECTOS GRANULOMÉTRICOS E QUÍMICOS DA GRAFITA}

Quase seis dezenas de amostras de composição e pesos variáveis foram coletadas no depósito em tela, para caracterização físico-química dos litotipos grafíticos e submissão destes a ensaios tecnológicos. Estes destinam-se ao estabelecimento de parâmetros para o aproveitamento econômico da grafita.

As litologias amostradas podem ser agrupadas basicamente sob os dois tipos de mineralização grafítica definidos no ítem anterior, ou seja, grafita-gnaisse e "brecha grafitosa". Os ensaios laboratoriais com os grafita gnaisses para identificar seus componentes e concentrar a grafita mostraram a seguinte composição mineralógica:

\begin{tabular}{lr}
\hline Quartzo & $54 \%$ \\
Grafita & $24 \%$ \\
Minerais do grupo & \\
da Caulinita & $9 \%$ \\
Hidróxidos de Ferro & $6 \%$ \\
Titanita provável & $6 \%$ \\
Hematita & $1 \%$ \\
\hline
\end{tabular}

Os dados relativos à "brecha grafitosa" foram obtidos apenas por cálculo das massas envolvidas nos ensaios de concentração, revelando um teor de grafita da ordem de $10 \%$, os demais constituintes distribuindose em $5,9 \%$ de matéria volátil e $84,2 \%$ de componentes conversíveis em cinzas (minerais do grupo da caulinita).

A análise granulométrica comparativa entre concentrados de flotação dos tipos gnáissico e brechóide é apresentada na Figura 6, onde se percebe que a grafita do tipo gnáissico se apresenta pouco mais grosseira que aquela do tipo brechóide na fração igual ou superior a 60 mesh. Cumulativamente, se assemelham bastante nas frações mais finas que 60 mesh. A análise química dos concentrados, no entanto, mostra diferenças mais sensíveis entre os dois tipos. A parte grosseira dos concentrados (> 100 mesh) mostra teores de carbono fixo de $87,8 \%$ para o tipo gnáissico e 90,6\% para o tipo brechóide, respectivamente. Já nas frações finas (< $100 \mathrm{mesh})$, tem-se um teor de carbono fixo de $86,4 \%$ para o tipo gnáissico e de $80,5 \%$ para o tipo brechóide. A média ponderada de teores, considerando a distribuição nas faixas granulométricas, indica $86,8 \%$ de carbono fixo para o tipo gnáissico e $83,4 \%$ para o tipo brechóide, evidenciando que o primeiro litotipo apresentou melhor resposta aos testes de recuperação da grafita.

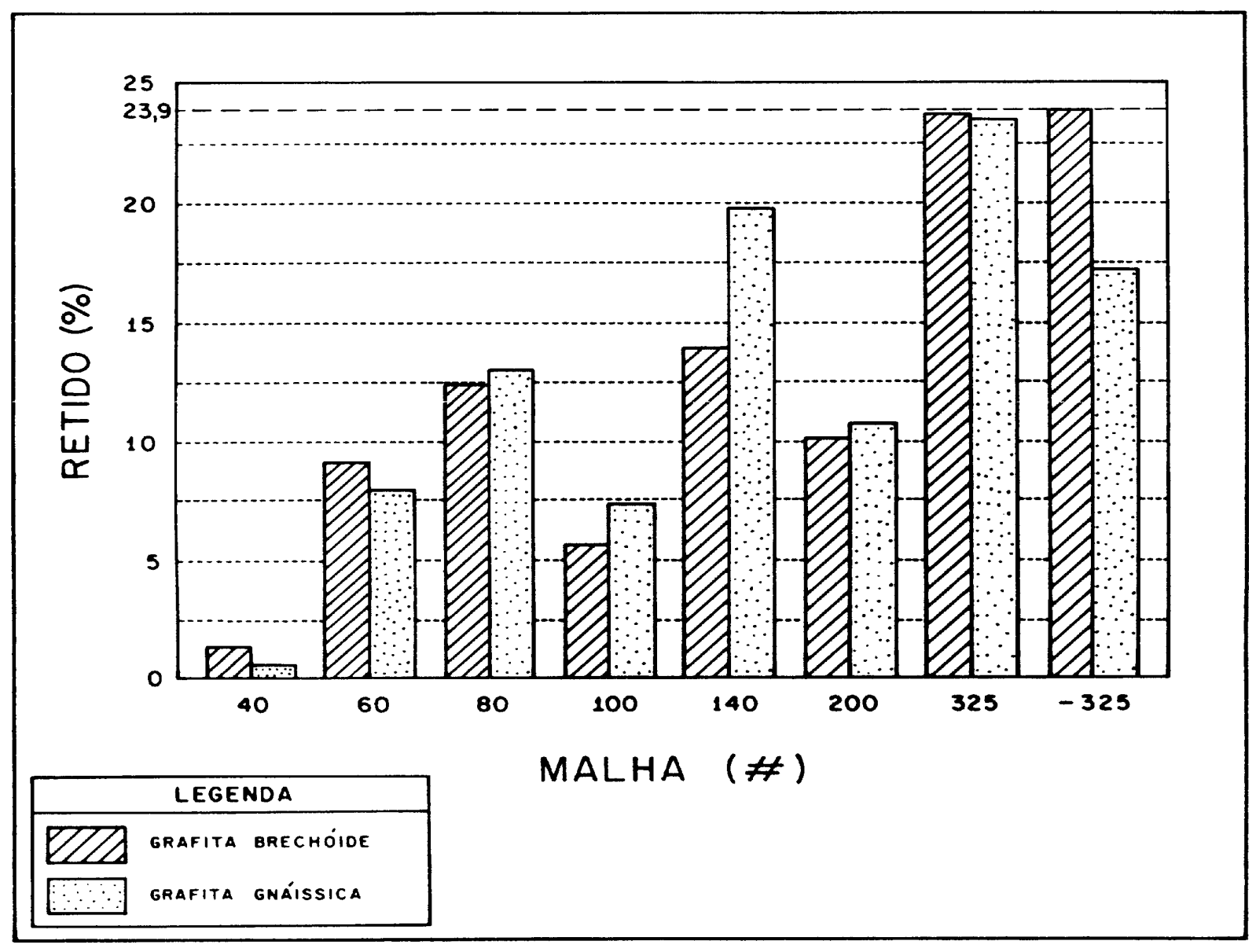

Figura 6:Análise granulométrica comparativa de concentrados de grafita proveniente de diferentes tipos litológicos.

Figure 6: Comparision of particle sizes of graphite concentrates from different lithologies. 


\section{DISCUSSÃO GENÉTICA DO DEPÓSITO}

A zona de cisalhamento de Traíras pode ser caracterizada como tendo sofrido várias reativações, evoluindo desde condições dúcteis geradoras de milonitos e típicas de nível crustal profundo até seus últimos espasmos sob condições rúpteis em nível crustal elevado, responsáveis pelas brechas de estrutura interna desordenada.

Iniciou-se com movimento direcional dextral em regime transcorrente, onde em situação adequada, como por exemplo numa sinuosidade côncava onde dominam condições de transtração (Harland 1971) desenvolveuse o rombocasmo a favor do qual deu-se uma intrusão ultrabásica, o que atesta a profundidade da estrutura.

A continuação da transcorrência fez com que as condições de transtração, que deram origem ao rombocasmo, mudassem para transpressivas. Sob estas novas condições a intrusiva ultrabásica foi foliada e atravessada por corpos miloníticos, e por silexitos (ultramilonitos? pseudotaquilitos da fase rúptil?)

Nos estágios mais tardios o cisalhamento se deu em níveis crustais mais elevados, sob condições rúpteis, quando foram gerados cataclasitos e brechas.

A recorrência de vários episódios cisalhantes provocou no interior das zonas de cisalhamento a deformação das estruturas anteriores, a geração de novas foliações e novas bandas de milonitos quartzosos, além da epidotização dos anfibólios.

Os corpos miloníticos cortam a ultrabásica, mas nunca são por ela cortados, o que permite datar de forma relativa a intrusão como simultânea à abertura do rombocasmo. O contraste químico entre a intrusiva ultrabásica e os milonitos que contém essencialmente quartzo, feldspato e grafita constitue um enígma em busca de uma explicação. Numa primeira hipótese a intrusão da ultrabásica teria sido acompanhada por carbono de origem mantélica que nela estaria disseminado sob forma de inclusões fluidas ou grafita intersticial. Na milonitização da ultrabásica, teria havido redução de grandes massas rochosas afim de gerar "residualmente" todo quartzo e feldspato dos milonitos enquanto o carbono disseminado se concentraria sob a forma de grafita. Mas este mecanismo teria que ser forçosamente acompanhado pela remoção pouco plausível de grandes quantidades de $\mathrm{FeO}$ e $\mathrm{MgO}$.

Uma alternativa seria a intrusão ultrabásica ter trazido com ela metassedimentos supostamente sotopostos aos gnaisses encaixantes do rombocasmo e tornados muito plásticos, tanto devido às altas pressões, como pelo seu conteudo em grafita. As milonitizações iniciais em níveis profundos teriam gerado as lentes grafíticas tabulares e permitido nelas o desenvolvimento das grandes palhetas de grafita (flakes) que constituem o atrativo econômico do depósito. Nos estágios mais tardios, a recorrência dos cisalhamentos em níveis crustais cada vez mais elevados, teve como efeito a geração localizada de cataclasitos e brechas, onde a granulometria das palhetas de grafita foi diminuída, o que se de um lado comprometeu o teor em flakes, do outro tornou o beneficiamento do minério mais efetivo.

\section{Comparação com Outros Depósitos}

Os argumentos aqui apresentados para uma estruturação do depósito de grafita da Fazenda Traíras permitem que o mesmo seja definido, resumidamente, como gerado sob condições de elevado strain e com associações mineralógicas características de alto/médio metamorfismo. Tratando-se de milonito é incerto se o carbono necessário para a geração de grafita proveio de horizontes sedimentares carbonosos, ou se de carbono juvenil disseminado na ultrabásica intrusiva.

A origem metamórfica a partir de sedimentos carbonosos é aceita para a maioria dos grandes depósitos de grafita atualmente em lavra atualmente (Krauss et al. 1988) como por exemplo em Reinder Lake (Canadá), Burnett (E.U.A.) e Madagascar. A exemplo destes depósitos, e também àquele recentemente desenvolvido em Lac-des-Iles (Quebec, Canadá) pela Stratmin Graphite Inc. (Goffaux 1992), o depósito da Fazenda Traíras está envolvido por rochas gnáissicas pré-cambrianas afetadas por fusão parcial, ocorrendo sob a forma de lentes muito alongadas segundo pelo menos uma dimensão e associado a intrusões básico-ultrabásicas.

Aos componentes de tectônica cisalhante dos eventos modeladores dos depósitos são feitas poucas referências na bibliografia consultada. Acredita-se que isto se deva ao fato da aplicação dos conceitos relativos a zonas de cisalhamento na modelagem de depósitos minerais, ser relativamente recente. É de se notar, no entanto, que para quase todos os depósitos conhecidos de origem metamórfica, cita-se a ocorrência de rochas muito silicosas ("quartzitos") fortemente orientadas, em constraste com os gnaisses encaixantes, e que poderiam, na verdade, tratar-se de quartzo milonitos relacionados a zonas de cisalhamento. Além disso, os modelos geológicos apresentados para os mesmos depósitos mostram invariavelmente marcantes lineamentos estruturais em um ou mais planos de representação, o que confirma a provável associação com importantes falhamentos.

No Brasil, os depósitos econômicos mais importantes em atividade de lavra sistemática, situamse nos municípios de Itapecerica (SE de Minas Gerais) e Pedra Azul (NE do mesmo Estado) cujos direitos minerários estão em poder da Cia. Nacional de Grafite Ltda. A literatura versando sobre os mesmos é escassa. Araújo et al. (1981), descreveram a ocorrência de Pedra Azul como "lentes encaixadas em rochas gnáissicas", com a gênese "relacionada à diagênese do material carbonoso, que com o desenvolvimento do metamorfismo perde progressivamente os compostos dos grupos oxigênio, nitrogênio e enxôfre, alcançando teor muito alto em grafita, quando no fácies granulito" (Brooks in Araújo et al. 1981). Sobre a ocorrência de Itapecerica pouco se sabe além de que os corpos grafitosos são constituídos de "xistos" sob a forma de lentes alongadas em superfície, encaixadas entre quartzitos muito fraturados e alterados, em um 
contexto de granitos e gnaisses.

Uma simples visita aos arredores da jazida de Pedra Azul, que comporta um grande número de ocorrências menores, mostra que o elemento tectônico é muito importante no controle da mineralização. Com efeito o distrito grafítico de Pedra Azul situa-se, como mostra o mapa da Figura 7, numa faixa NW-SE com $12 \mathrm{~km}$ de largura, flanqueada ao sul por granito-gnaisses ondulados com mergulhos fracos a moderados ora para norte ora para sul, e ao norte por metassedimentos de grau médio a alto correlacionados ao Grupo Macaúbas. No interior da faixa predomina uma forte estruturação vertical com extenso desenvolvimento de quartzomilonitos formando cristas de serras paralelas e onduladas no meio de gnaisses miloníticos, cuja litologia pretérita ainda está por ser definida. Os corpos grafíticos encontram-se, concentrados ora, sob a forma de lentes, próximos aos quartzo-milonitos, ora sob a forma mais ou menos disseminada em gnaisses miloníticos extremamente dobrados, como é o caso da Jazida de Pedra Azul.

Desta forma, o elemento tectônico e mais especificamente as zonas de cisalhamento em níveis crustais inferiores, onde predominam condições de fácies anfibolito alto a granulito, constituem sem dúvida um dos metalotéctos mais importantes na geração de depósitos econômicos de grafita.

\section{AGRADECIMENTOS}

Os autores agradecem à Mineração Quaranas Ltda. detentora dos direitos minerários da área objeto do presente estudo, pela permissão em publicar alguns dados da pesquisa feita pelos autores em nome da Andrade Gutierrez Mineração Ltda.

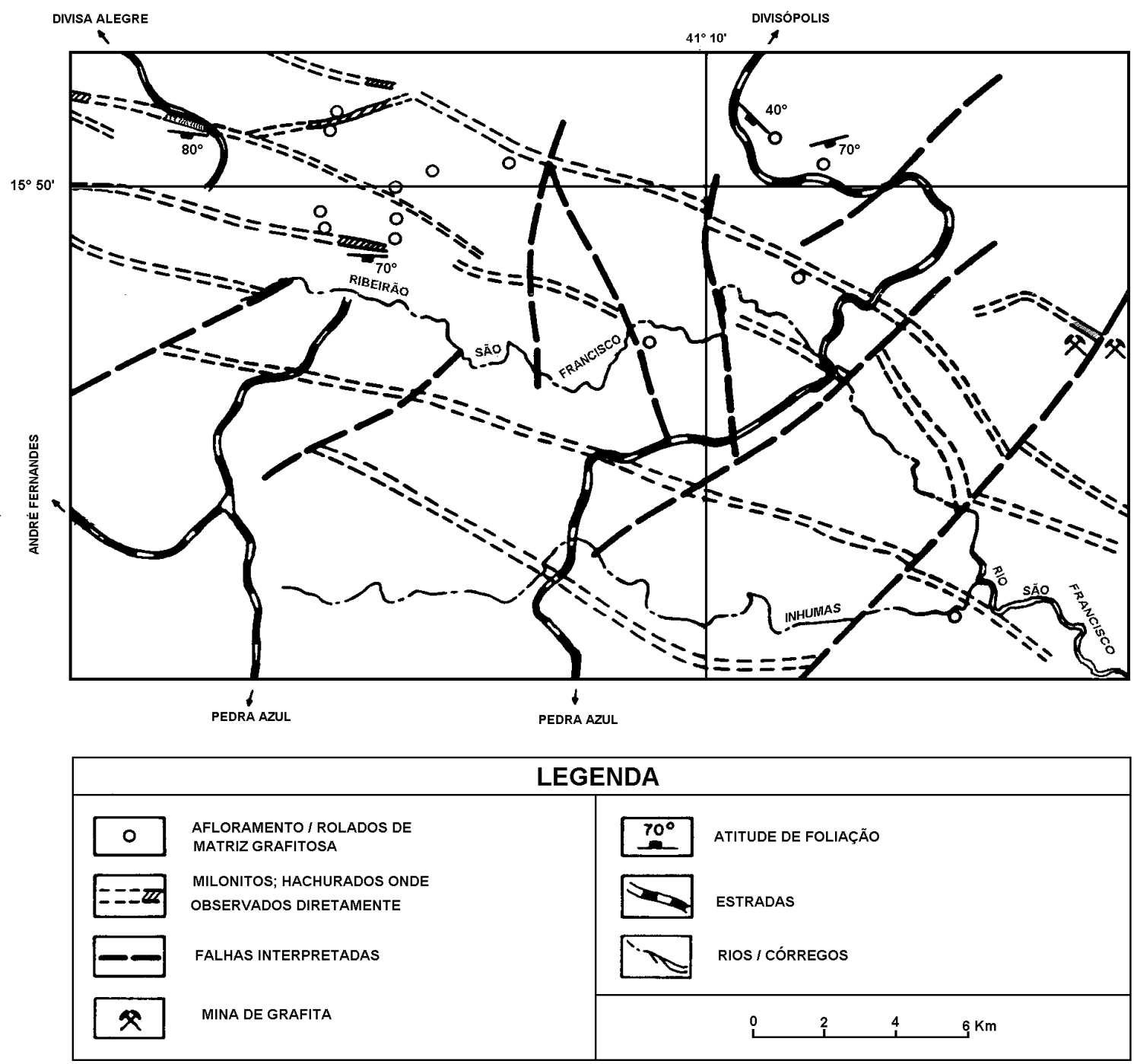

Figura 7:Esboço das zonas de cisalhamento do Distrito Grafítico de Pedra Azul, MG.

Figure 7: Sketch map of the shear zones of the graphite district Pedra Azul, MG. 


\section{REFERÊNCIAS BIBLIOGRÁFICAS}

ARAÚJO, A.G. de; LIMA, J.O.A. de; MELLO, M.P. de; MARTINS Jr., P.P.; LITWINSKI, N. 1981. Síntese dos Principais Recursos Minerais do Vale do Jequitinhonha-MG. Belo Horizonte, SBG Núcleo MG, p. 27-28 (Boletim 2).

BATES, R. L. \& JACKSON, J.A. 1980. Glossary of Geology. 2 ed. Falls Church, VA. American Geological Institute. p. 536.

GOFFAUX, D. 1992. Stratmin Graphite Inc.: A Unique Mine Story. Littleton, CO. Society for Mining, Metallurgy and Exploration, Inc. p. 1-2. (Preprint Report 92-104).

HARLAND, W. B. 1971. Tectonic transpression in Caledonian Spitzbergen. Geol. Mag. 108 (1): 27-42.

KRAUSS, U.H.; SCHMIDT, H.W.; TAYLOR, Jr., H.A. \& SUTPHIN, D.M. 1988. Natural Graphite - Report. Denver, CO,USGS. 29 p. (Circular 930-H).

MASCARENHAS, J.F.; PEDREIRA, A.J. de C.L.; GIL, C.A.A.; NEVES, J.P. das; OLIVEIRA, J.E. de; SILVA FILHO, M.A. da; MARINHO, M.M. 1979. Geologia da Região Centro-Oriental da Bahia; Projeto Bahia, Bahia II e sul da Bahia: Relatórios integrados. Brasília, DF, DNPM. 128 p. (Série Geologia no II, Seção Geologia Básica no. 8).

PEDREIRA, A.J; ARCANJO, J. B.A.; PEDROSA, C.J.; OLIVEIRA, J.E. de; SILVA, B.C.E. 1975. Projeto Bahia: Relatório Final. Salvador, DNPM/CPRM. Vol. I e III.

SAMPAIO, H.A. \& SILVA FILHO, R. A. da. 1986. Mapa Metamórfico do Estado da Bahia: Texto Explicativo. Salvador, SME/SGRM. 69 p.

SEYFERT, C.K. 1987. The Encyclopedia of Structural Geology and Plate Tectonics. New York, NJ, (Van Nostrand Reinhold Co. Inc.) p. 674-675. 